\title{
THE EFFECT OF PROSTIGMIN ON THE URINARY EXCRETION OF POTASSIUM IN THE NORMAL SUBJECT
}

BY

\author{
J. N. CUMINGS * \\ (ReCeived 18Th November, 1941)
}

From the Biochemical Department, National Hospital, Queen Square, London

Previous work (Cumings, 1940) on the effect of prostigmin (mgm. i) in patients suffering from myasthenia gravis showed that although potassium was liberated from affected muscles and circulated in the blood, the urine did not show any increased amount of potassium. It was assumed that prostigmin did not in any way cause this retention of potassium in that it had no effect on the kidney, and upon this assumption certain deductions were made. The present paper describes an attempt to show that this assumption was correct.

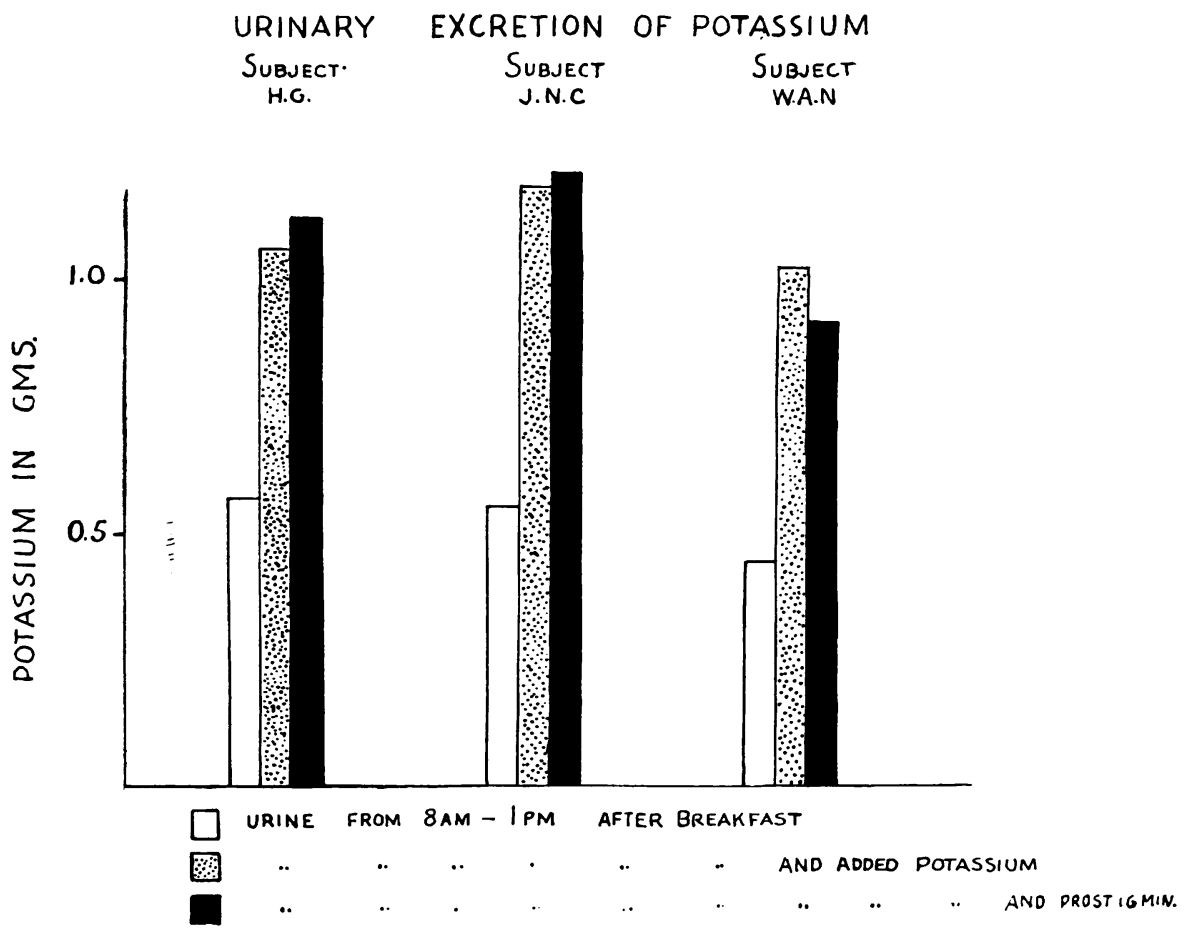

Fig. 1.

235 
The urinary excretion of potassium was studied in three normal subjects. All urine passed between 8 a.m. and 1 p.m. was collected, breakfast having been taken before 8 a.m. after the bladder had been completely emptied. No food was taken during the experimental periods and a similar breakfast was taken on each day. Three test periods were conducted, and in the first urine was collected after breakfast only, during the second period $1 \mathrm{gm}$. of potassium as dipotassium hydrogen phosphate was taken immediately after breakfast and the specimens of urine again collected. Finally the urines were collected as in the second period, but with prostigmin injections immediately after the added potassium had been given. Urine was also collected from 1 p.m. to 5 p.m., but as most of the added potassium was excreted during the morning, the results of these examinations are not recorded.

Fig. 1 shows the results obtained, from which it is seen that prostigmin has had no effect on the excretion of potassium, as the amount of potassium excreted after the prostigmin injections is slightly higher in two of the subjects and only slightly lower in one subject, who it is seen also excreted less potassium than either of the other two. It is evident, therefore, that the previous assumption was correct, and that prostigmin was not the direct cause of the retention of potassium in the patients with myasthenia.

* An expenses grant was received from the National Hospital Research Fund for which my thanks are due.

\section{REFERENCE}

Cumings, J. N. (1940). J. Neurol. Psychiat., 3, 115. 